\title{
INVESTIGATIONS ON CERAMIC COATED DIESEL ENGINE WITH BRASS PISTON MATERIAL
}

\author{
S. Sunit Kumar Reddy ${ }^{1 *}$ and V. Pandurangadu ${ }^{2}$ \\ ${ }^{1}$ Department of Mechanical Engineering, N.B.K.R.I.S.T., Vidyanagar-524 413, Nellore (Dt.), A.P., INDIA \\ ${ }^{2}$ Department of Mechanical Engineering, JNT University, Anantapur, A.P., INDIA \\ *Corresponding e-mail: sunilkumarreddy1974@gmail.com
}

\begin{abstract}
With the enormous energy demand and environmental concern the interest on the alternate fuels to the diesel engines has been increased. Among all the fuels alcohols have received a considerable attention because these are bio-based, renewable and are oxygenated. But due to its properties they require higher operating temperatures in the combustion chambers. Hence in the present work a ceramic coated insulated engine is developed by incorporating an air gap between piston skirt and crown for the study of alcohols performance and emission characteristics. The combustion efficiency depends on the mixture strength, piston material and turbulence in the chamber. So, in this work an attempt is made with brass piston and brass insert with nine and twelve grooves. Among all the pistons tested the brass insert with nine grooves is best in terms of engine performance and emissions. With the elevated temperatures the main problems faced are drop in volumetric efficiency and lubricating oil deterioration and can be avoided with turbo compounding system and new lubricants.
\end{abstract}

Keywords: ceramics, Alcohols, piston inserts, low heat rejection engines, brass piston.

$\begin{array}{cl}\text { Abbreviations } & \\ \text { LHR } & \text { Low heat rejection } \\ \text { PSZ } & \text { Partially Stabilized Zirconium } \\ \text { DI } & \text { Direct Injection } \\ \text { BSFC } & \text { Brake Specific fuel Consumption } \\ \text { TDC } & \text { Top Dead center } \\ \mathrm{Y}_{2} \mathrm{O}_{3} & \text { Yttrium Oxide } \\ \mathrm{ZrO}_{2} & \text { Zirconium Oxide } \\ \mathrm{Zr}(\mathrm{OH})_{4} & \text { Zirconium Hydroxide } \\ \mathrm{Y}(\mathrm{OH})_{4} & \text { Yttrium hydroxide } \\ \mathrm{A} / \mathrm{F} & \text { Air-fuel ratio }\end{array}$

\section{INTRODUCTION}

Although the researchers claim that the diesel engines may be converted to alcohol engines without sacrificing efficiency and emission standards, in most of their studies, the detailed performance and combustion characteristics have not been disclosed. It is well known that the engines lose some amount of energy developed in the combustion chamber through the cooling system. If this heat transfer is restricted by the ceramic materials, the engine combustion performance can be improved.

Among various fuels tested in diesel engines, alcohols are considered as good substitute for diesel because these are bio-based and renewable. But due to the alcohol properties it requires high compression ratio in the diesel engines ${ }^{1}$, which makes the engine bulky. So in the present work a ceramic coated engine is developed with the insulation of the combustion chamber ${ }^{2,3,4}$. Ceramics have a higher thermal durability and lower thermal conductivity that controls the temperature distribution and heat flow in the structure. Lower heat rejection from the combustion chamber through thermally insulated components causes an increase in available energy that would increase the in-cylinder work and the amount of energy carried by the exhaust gases. This could also be also utilized. Significant amount of research work has been carried out on the insulated engine.

Chan and $\mathrm{Khor}^{8}$ reported 4 to $7 \%$ improvement in fuel consumption in single cylinder DI diesel engine. This was accomplished by using constant air flow rate with boosting pressure with $1 \mathrm{~mm}$ thick PSZ coating to the cylinder head face and the valve heads by placing a short solid PSZ cylinder liner in the area above the piston rings and heat insulated steel piston. Nagalingam et al. ${ }^{14}$ converted the four stroke diesel engine into LHR engine with the insulation of the components and conducted the experiments with alcohol and concluded that the performance of the engine with the insulation was increased and the emissions are also reduced considerably. T. Morel $^{5}$ et. al achieved thermal efficiency at all loads for both heavy and light engines with the various level of insulation at constant peak pressure and $\mathrm{A} / \mathrm{F}$ ratio. The brake thermal efficiency of the engine is improved by $8 \%$. Heat rejection is reported to be decreased while exhaust temperature is increased. Miyairi et al. ${ }^{7}$ reported reduction in BSFC by $7 \%$ under naturally aspirated conditions in single cylinder DI diesel engine. In this attempt the fuel injection pressure and the amount of fuel injected is kept constant and the cylinder liner is water cooled. The chamber walls are insulated with PSZ. Kamo et al. ${ }^{6}$ 
conducted experiments with $0.13 \mathrm{~mm}$ thick thermal barrier coating of PSZ for the piston and cylinder head and $0.5 \mathrm{~mm}$ thick coating for cylinder liner. They reported that 5 to $6 \%$ improvement in fuel efficiency at all loads and speeds. They observed with this, higher premix combustion, lower diffusion combustion, reduction heat transfer loss, higher heat release in the combustion chamber. Murthy et al. ${ }^{9}$ reported the results of their investigations on LHR diesel engine with $3 \mathrm{~mm}$ air gap between piston skirt and insert with Nimonic alloy crown. This reveals that the performance is deteriorated at the available injection timing and pressure. At peak loads the $\mathrm{BSFC}$ is decreased by $12 \%$ while smoke levels by 16 $\%$ but NOx levels are increased by $34 \%$ with an injection timing of $32{ }^{0} \mathrm{bTDC}$. Wallace et al. ${ }^{11}$ have reported the use of a thermal barrier piston in the adiabatic engine and developed the temperature distribution analysis and reported that the piston top temperature were higher by around $400^{\circ} \mathrm{C}$ for the thermal barrier pistons.

From the literature it is observed that much amount of heat is lost through the piston. Due to the high latent heat, for the burning of alcohols, heat is to be retained in the combustion chamber. Thus the main aim of this study is to investigate the performance and emissions of a diesel engine operating with a piston made of brass material with and without grooves and to compare these results with those obtained from the diesel fuel. The brass crown is also same in size of the original piston and can be interchangeable ${ }^{9,10}$.

\section{MATERIALS AND METHODS}

The main aim of the investigation is to convert the conventional diesel engine into the ceramic insulated engine for the burning of alcohols which is considered to be the perfect replacement for the diesel fuel. The following are the main phases involved in the total experiment.

1. Production of Ethanol (alcohol)

2. Preparation of insulated engine

3. Investigations with different piston inserts

4. Experimental program

5. Results and discussions

\section{Production of ethanol}

The alcohol is produced by the fermentation of sugarcane juice and molasses. Because these are clean, affordable and low-carbon biofuels, they emerged as a leading renewable fuel for the transportation sector. The major advantage of ethanol is it provides clean air (it adds oxygen to diesel fuel and reduces the air pollution and harmful emissions). They also reduce knocking tendency and generates more power to the engines. Figure 1 depicts the steps involved in the production of ethanol.

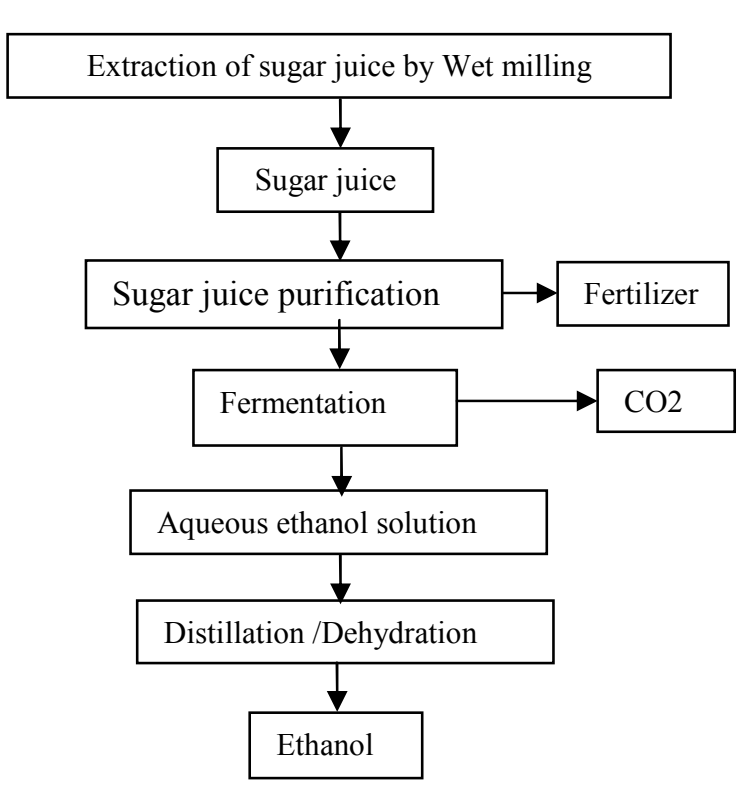

Figure 1. Steps in the production of Ethanol.

\section{Preparation of insulated engine}

For the combustion of alcohols in diesel engines it requires higher prevailing temperatures in the combustion chambers. For that the combustion chamber of the insulated engine is to be insulated.

The insulated engine mainly consists of the important components like piston, cylinder liner, cylinder head and valves. The complete method of insulation is explained as follows.
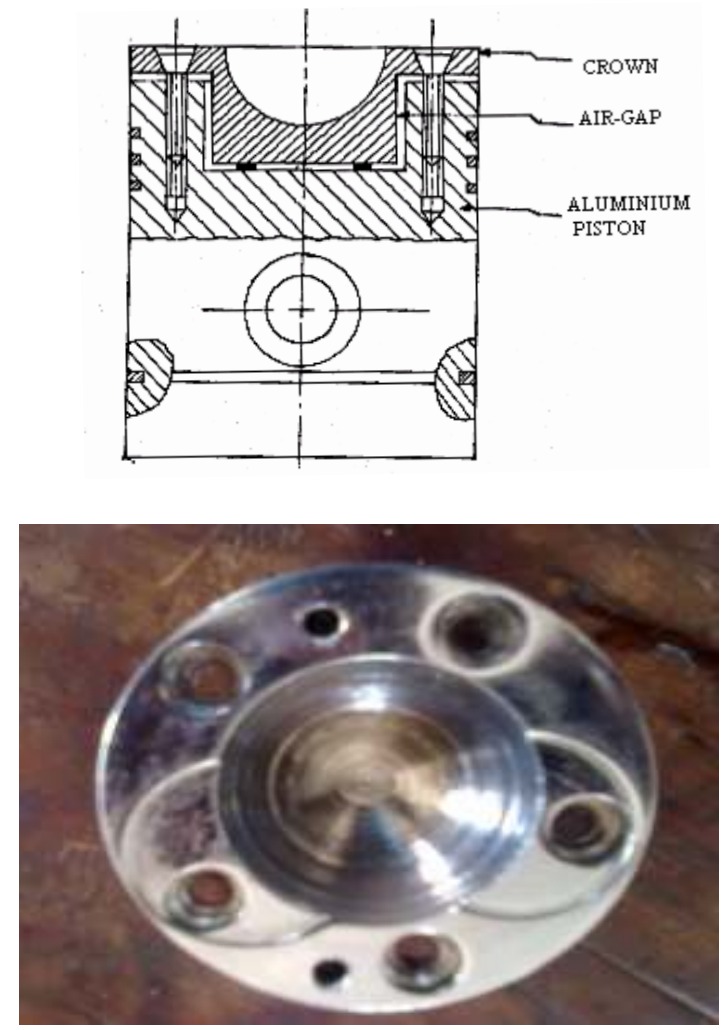

Figure 2. Air gap insulated Aluminum crown

(a) Line diagram (b) Photograph of aluminum crown. 


\section{Insulation of the piston}

In the present experiment based on the available literature an air gap of $2 \mathrm{~mm}$ is provided between piston crown and skirt. The crown and skirt is connected with copper and steel gaskets. The air gap between the two components acts as an insulator for the heat transfer through the piston and this makes the combustion smooth in the controlled phase. Figure 2 shows the insulated aluminum piston.

\section{Insulation of cylinder head and valve}

The ceramics have better heat and wear resistant characteristics which retains the heat in the combustion chamber. This also improves the combustion efficiency and reduces the pollutant emissions. For the present experiment Ceramic is chosen as the insulating material because of its low density, high thermal stability, stability in severe chemical environment, low thermal conductivity and favorable strength and creep behavior ${ }^{12,18}$.

The ceramic insulated powder required for the coating is obtained as follows. Zirconia is usually produced from the zircon, $\mathrm{ZrSiO}_{4}$. To produce zirconia from zircon, the first step is to convert zircon to zirconyl chloride. It can be done by the following series of reactions:

\section{$\mathrm{ZrOCl}_{2} 8 \mathrm{H}_{2} \mathrm{O}+$ Stabilizer $\left(\mathrm{Y}_{2} \mathrm{O}_{3}\right)+\mathrm{HCl} \longrightarrow$}

Solution
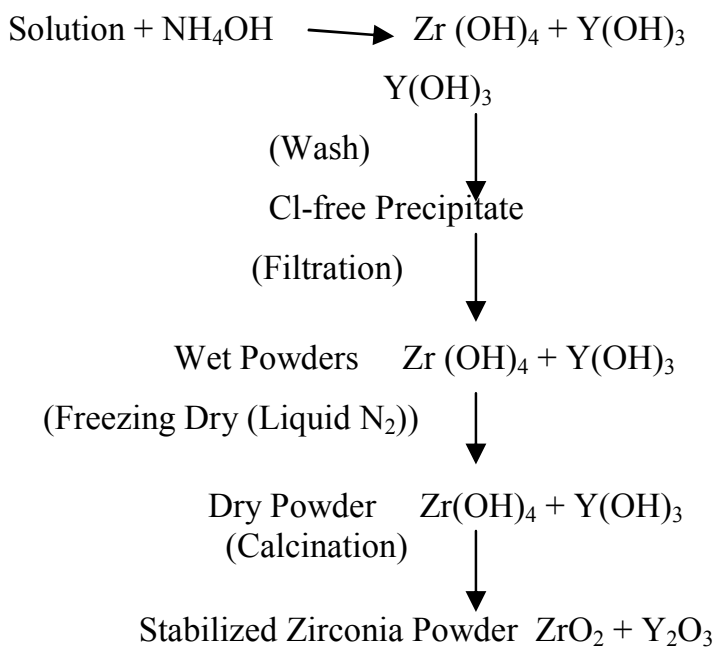

Thus with the available insulated powder cylinder head and valves are coated. In this the following processes are involved

- Pre-cleaning and pre-machining of the cylinder head and valve surfaces.

- Coating of the nano ceramic material PSZ with plasma spraying process

- Final finishing operations like grinding, lapping, polishing and cleaning.
With the above specified method, the cylinder head and valves are insulated to a depth of $0.5 \mathrm{~mm}$. The PSZ coated cylinder head and valves are shown in Fig. 3.

\section{Insulation of Cylinder Liner}

The movement of the piston within the cylinder is a hindrance for the insulation of the liner on its inner surface. Hence the insulation is to be provided outside the liner. In this case air with its low thermal conductivity is used as the insulating medium. This insulation of the liner reduces the heat transfer from the engine cylinder to the cooling water.

All these insulated parts described above were interchangeable with the standard engine.

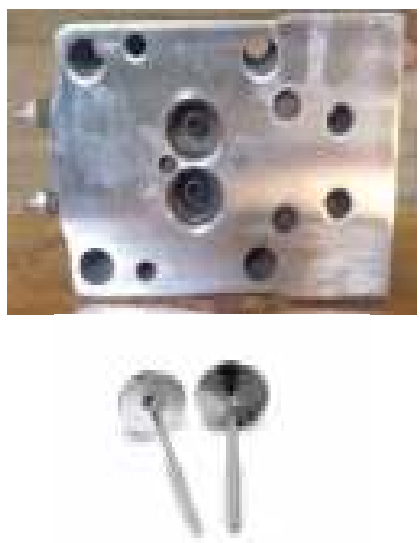

Figure 3. PSZ coated cylinder head and valves.

\section{INVESTIGATIONS WITH DIFFERENT PISTON INSERTS}

The ceramic engine consists of two parts on piston - the top crown is made of low thermal conductivity material and the body of the piston. In the present work brass piston was screwed to the aluminum body of the piston with $2 \mathrm{~mm}$ air gap between the crown and the body of the piston. This optimum thickness is provided based on the previous experiments. Along with the brass piston insert, brass piston insert with nine and twelve number of grooves are designed for the turbulence and to retain heat in the combustion chamber. The size and the shape of the groove, is selected in such a way that maximum number of grooves will be generated on the brass piston with the available technology. The shape of the groove selected for the experiment is in the form of elliptical section which covers from the squish area of the piston to the end of the piston crown. The elliptical groove is opened to the squish area and is closed in all the other directions. The compression gases will enter into the grooves and will have good swirling, so that it will form homogeneous mixture. This brass crown piston is further knurled to increase its surface area to facilitate better heat transfer from the combustion gases to the brass crown. The pistons tried in this work are shown in Fig. 4, 5 and 6. 


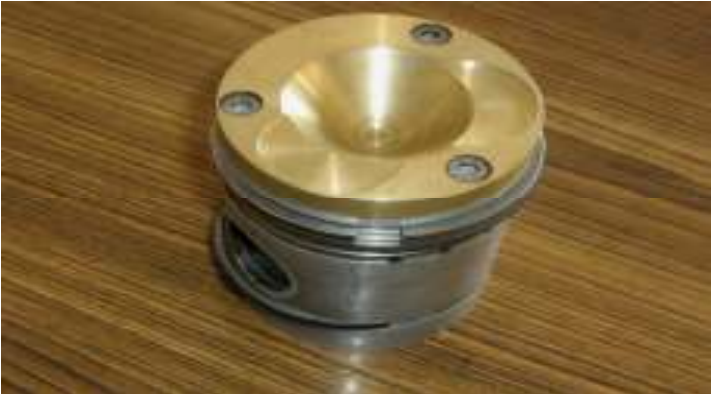

Figure 4. Plain brass crown piston (BP).

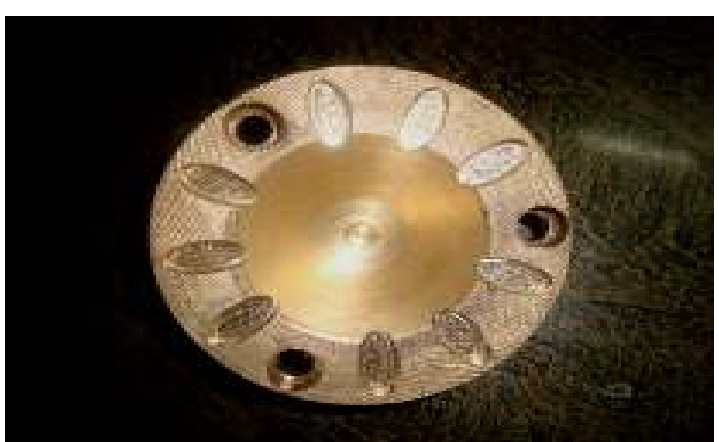

Figure 5. Brass crown piston Crown with nine grooves (BP 9).

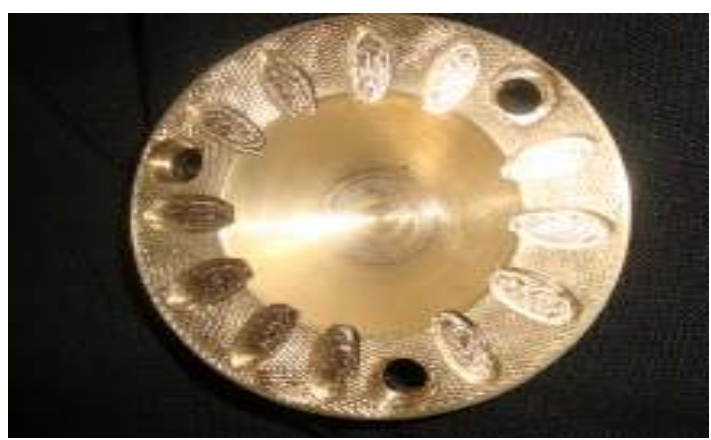

Figure 6. Brass crown piston Crown with twelve grooves (BP12).

\section{EXPERIMENTAL PROGRAMME}

The experimental set up layout used for the investigations of ceramic coated diesel engine is shown in Fig. 7. The experiments were carried out on a naturally aspirated water cooled, 4-cylinder DI diesel engine. The specifications are given in Table 1.

The insulated engine was connected to the eddy current dynamometer for applying the load. It also consists of a control system for adjusting its speed and torque. The manufacture's recommended injection pressure is 180 bar. Air suction rate and exhaust air flow rates are measured with the help of an air box method. With the available fuel injection pressure more amount of alcohol will be injected into the combustion chamber which cools the engine. This is because of its low viscosity and high latent heat. So for the present work the fuel injection pressure is reduced to 165 bar which is based on experiments.
Table1. Engine Specifications

\begin{tabular}{|l|l|}
\hline Type & $\begin{array}{l}\text { Vertical, Water cooled, } \\
\text { Four stroke }\end{array}$ \\
\hline Make & Kirloskar \\
\hline No. of cylinder & One \\
\hline Bore & $80 \mathrm{~mm}$ \\
\hline Stroke & $110 \mathrm{~mm}$ \\
\hline Compression ratio & $16.5: 1$ \\
\hline Maximum power & $3.68 \mathrm{~kW}$ \\
\hline Speed & $1500 \mathrm{rpm}$ \\
\hline Dynamometer & Eddy Current Dynamometer \\
\hline
\end{tabular}
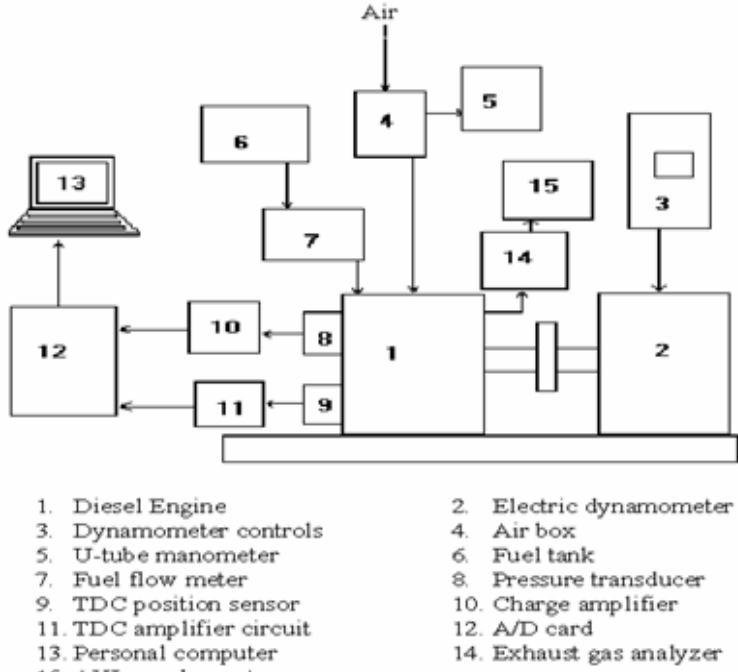

14. Exhaust gas analyzer

Figure 7. Insulated Engine Experimental set up

Exhaust gas temperatures are measured with Nickel-Nickel Chromium thermocouples. Pollution levels of smoke and NOx were recorded with AVL smoke meter and non-dispersive infrared (NDIR) AVL exhaust gas analyzer. Engine RPM is measured with an electro-magnetic pick up in conjunction with a digital indicator of AQUTAH make. The diesel fuel and alcohol fuel are subjected to performance and emission tests on the normal engine (NE) and insulated engine with various piston inserts (BP, BP9 and BP12). In this study, the diesel engine is not modified during all the tests. Before each test, the engine is allowed to operate with new oil and readings are recorded after the engine is stabilized.

\section{RESULTS AND DISCUSSIONS}

The performance and emission characteristics of different fuels (diesel and alcohol) at various load conditions are analyzed and the results are presented in the following sections in detail. 
The clearance volume on the piston crown increases with the increase in the number of grooves. Hence the compression ratio of the engine decreases which leads to the poor combustion. The compression ratio for six number of grooves on the piston crown is more but the turbulence generated in the combustion chamber is less than nine and twelve grooves pistons. Due to the low turbulence, the formation of homogeneous mixture is less and further the combustion is poor. With 12 number of grooves, the relative decrease in compression ratio is more, but the turbulence created is more than 6 and 9 groove pistons. Though the turbulence is more, due to lower compression ratio the performance dropped. With 9 number of grooves the poor combustion due to reduction in compression ratio is compensated by better turbulence and insulated conditions. Further if the number of grooves on the piston is increased the performance still drops.

\section{Exhaust gas temperature}

The lower thermal conductivity of the ceramic material and the brass piston restricts the heat flow through the engine components. This increases the heat in the combustion chamber, decreases the viscosity of the fuel, further it improves the atomization of fuel and combustion process. The variations of exhaust gas temperature for various pistons are illustrated in Fig. 8. The exhaust gas temperature for brass piston is $560^{\circ} \mathrm{C}$ and for aluminum it is $510^{\circ} \mathrm{C}$ at full load with diesel. The exhaust gas temperature of alcohol with aluminum piston is slightly lesser than diesel fuel.

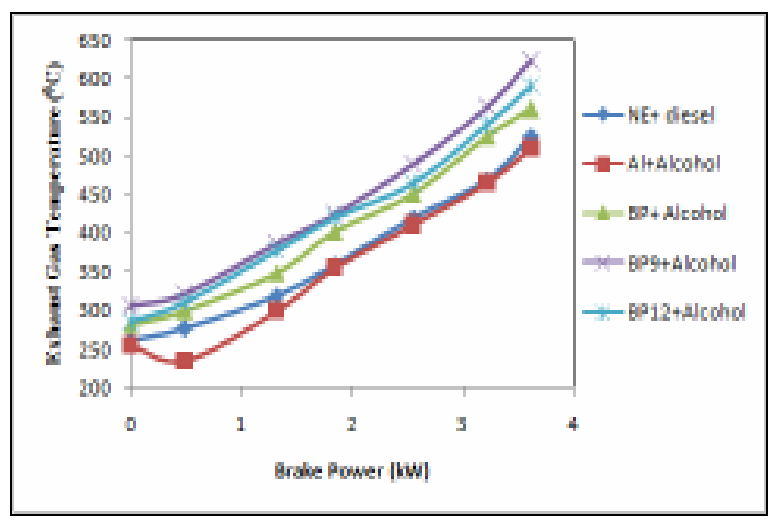

Figure 8. Variation of Exhaust gas temperature for different piston materials.

The complete burning of alcohol in the combustion chamber is attributed to the oxygen content in the alcohol and the insulated environment in the chamber. The turbulence generated by the grooves with the brass piston enhances the combustion and further it boosts' up the exhaust gas temperature. In this the maximum temperature at the rated load is attained with BP9 and is $2.32 \%$ more than BP and is followed by BP12. This high tempera- ture exhaust gas energy can be recovered by turbo compounding system.

\section{Brake thermal efficiency}

The complete combustion of fuel depends on the temperature in the combustion chamber. The ceramic insulation in the chamber and brass piston reduces the heat transfer to cooling medium and through the piston. Further the air swirl in the combustion chamber provides homogeneous mixture. This enhances the heat in the combustion chamber and combustion efficiency. Figure 9 shows that the variation of brake thermal efficiency of the ceramic insulated engine with the power output for various piston inserts and fuels. In all cases, the efficiency is increasing with increase in loads. This is due to the reduction in heat loss.

So the brake thermal efficiency of brass crown piston is increased by about $4 \%$ compared to aluminum crown piston at rated loads. Similarly with the air turbulence the brake thermal efficiency increased by about $2.53 \%, 1.58 \%$ for BP9 and BP12 compared to BP at rated loads. This is endorsed to the alcohols fuel injection pressure and oxygen content in the alcohol.

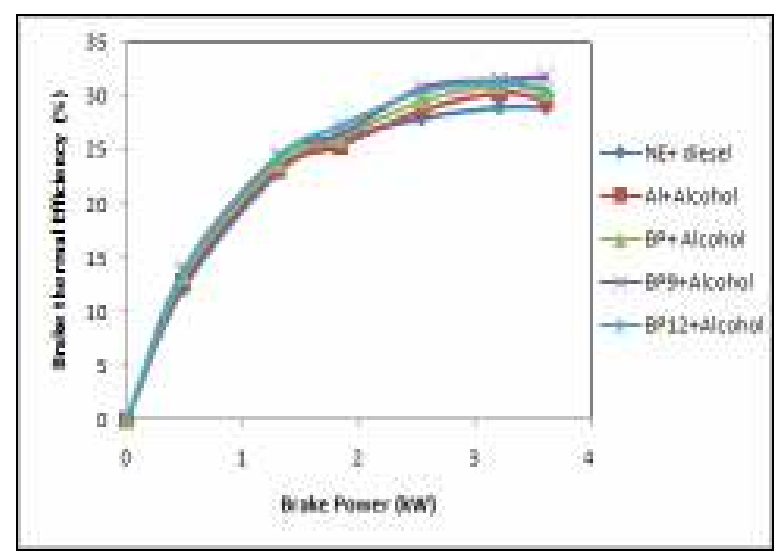

Figure 9. Variation of brake thermal efficiency for different piston materials.

\section{Volumetric efficiency}

The higher temperatures in the combustion chamber with the ceramic insulation, brass pistons and air swirl trims down the density of the inward charge and further drops the volumetric efficiency and plunges the power output. Figure 10 depicts the volumetric efficiency variation for various piston materials.

The volumetric efficiency of the insulated engine with aluminum piston varies from $85 \%$ to $82 \%$. This is attributed to the prevailing temperatures in the combustion chamber. It is observed that the drop in volumetric efficiency is more for BP9 and is about $1.2 \%$ as compared to BP at rated load and for BP12 it lie in between BP and BP9.

So the drop in power output of an insulated engine 
can be compensated by either supercharging or turbo charging.

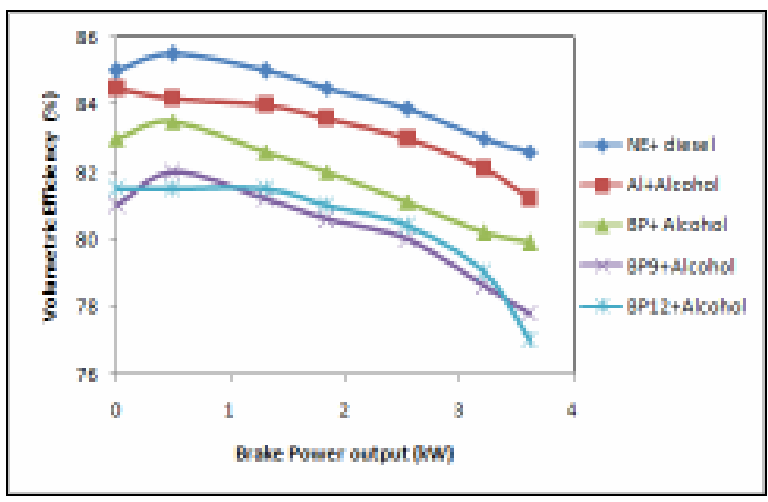

Figure 10. Variation of volumetric efficiency for different piston materials.

\section{Smoke density}

The smoke in the exhaust is due to the lack of oxygen, inferior operating temperatures and incomplete combustion. But in the present work, the brass piston material with its lower thermal conductivity maintains higher temperatures in the combustion chamber and further with the inherent oxygen content in the alcohol, the oxidation of the soot particles takes place which reduces the smoke emissions. Generally the smoke intensities are measured by opacity test. Figure 11 depicts the variation of smoke emissions for different piston materials. From the graph it is observed the increasing tendency of smoke intensities with the load and this is due to formation of rich mixtures in the chamber. With the ceramic insulation, brass piston material, the brass piston showed the lowest smoke emissions over the operating range and is about $19.8 \%$ to the aluminum piston. The drop is further increased with air turbulence in the chamber with grooves on the brass piston and is 16 percent compared to BP. The smoke intensity of the BP12 is in between BP and BP9.

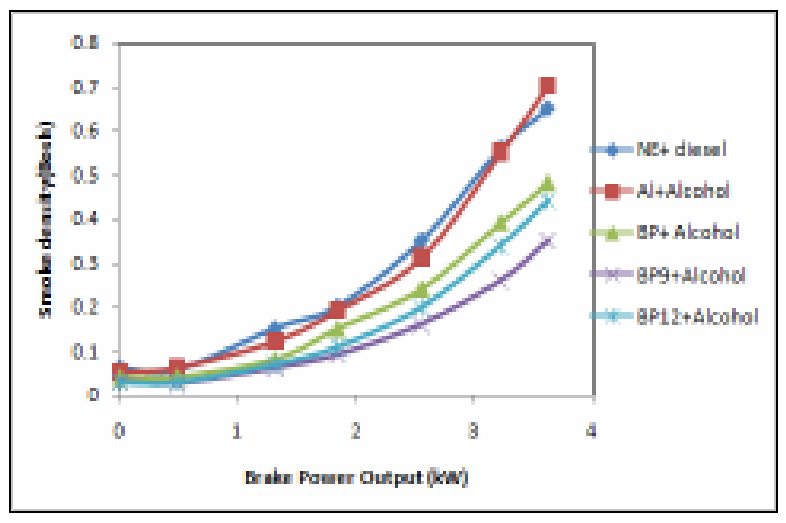

Figure 11. Variation of Smoke intensity for different piston materials.

\section{Hydrocarbon emissions (HC emissions)}

The amount of unburnt hydrocarbons present in the exhaust as a function of load for different piston crowns is illustrated in Fig. 12. The main sources of these emissions in diesel engine are lean mixing, burning of lubricating oil and wall quenching. In spite of rich air-fuel mixture due to the lower volumetric efficiency, the $\mathrm{HC}$ emissions are reduced considerably due to the completion of combustion of the fuel with hot combustion chamber. As the load is increased, it would increase the alcohol and this could increase oxygen content; reduce the density; leading to improved spray and atomization, better combustion and lower HC emissions. From the graph it is observed that at the rated load with the brass crown piston, the reduction in $\mathrm{HC}$ emissions is about $17.3 \%$ compared to aluminum piston.

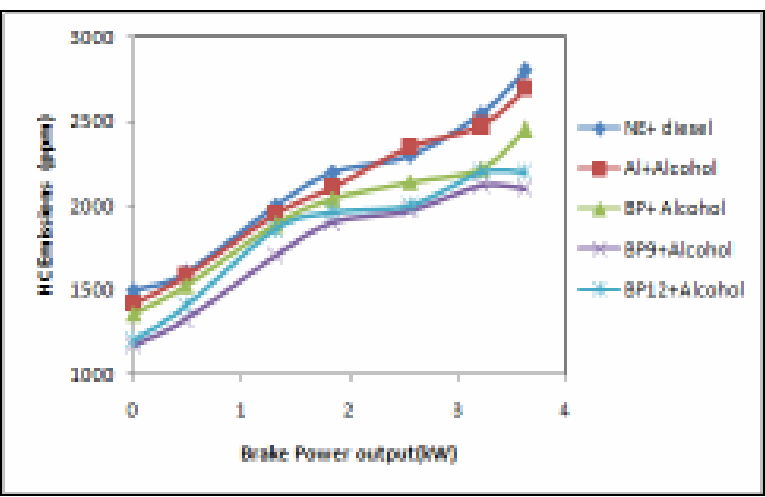

Figure 12. Comparison of Hydrocarbon emissions with power output

Due to hotter combustion chamber with the turbulence by the grooves on the brass piston and the presence of oxygen with alcohol, the HC emissions are reduced by $9.26 \%$ and $7 \%$ for $\mathrm{BP} 9$ and $\mathrm{BP} 12$ compared to BP.

\section{Nitrogen oxide emissions (NOx emissions)}

The formation of nitrogen oxide emissions depends on the heat transfer rate and evaporation rate of the fuel. This increases further, with the availability of oxygen and the higher prevailing temperatures in the chamber.

Figure 13 illustrates the variation of $\mathrm{NOx}$ emissions with various piston material inserts of the ceramic coated engine. With the ceramic insulation and brass piston material the heat in the chamber is higher which further increases the evaporation rate of the fuel. This increases the combustion efficiency due to the availability of oxygen in alcohol. So the NOx emission tendency also increases. But the amount of NOx formation is slightly reduced by the latent heat of vaporization of alcohol. The increase in NOx emissions with brass crown piston is about $6.1 \%$ compared to aluminum piston at rated load. The turbulence in the combustion chamber with the 
grooves on the brass piston enhances the temperature further. So NOx formation is more with BP9 and $\mathrm{BP} 12$ and is about $3.4 \%$ and $0.9 \%$ more than $\mathrm{BP}$ at rated load.

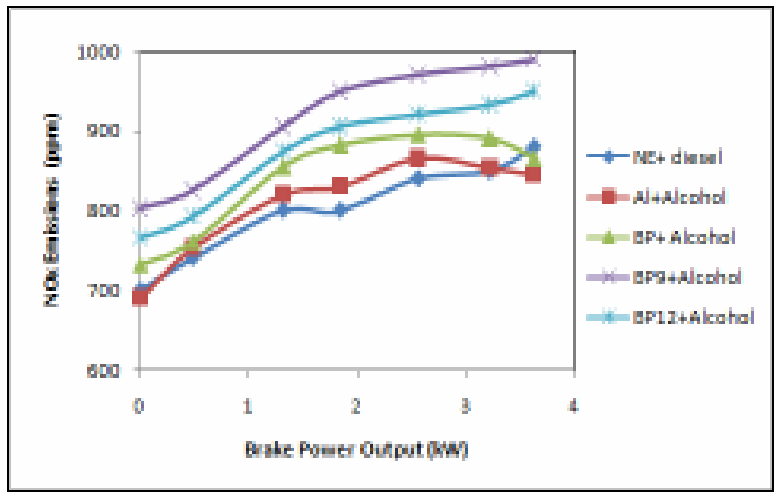

Figure 13. Variation of Nitrogen Oxide emissions for different piston materials.

\section{CONCLUSIONS}

Following are the conclusions drawn based on the experimental results with diesel and alcohol as fuel

1. The brake thermal efficiency and exhaust gas temperatures with brass piston are more because the brass material due to its lower thermal conductivity acted as a regenerator.

2. With the turbulence BP9 performed well in terms of emissions and efficiency.

3. The insulated components in the engine increase the available energy at the chamber and are evident with the exhaust gas energy which can be used to run a low pressure turbine.

4. The volumetric efficiency of the ceramic engine is reduced with the higher operating temperatures of the chamber. This can be recovered with turbocharging system.

5. With the higher temperature in the chamber NOx emissions are more with BP9 compared to all other pistons

Good homogeneous mixture formation, complete combustion and lower pollutant emissions are the main important factors for the high-quality diesel engine performance. These factors are highly influenced by viscosity, density, amount of oxygen present in the fuel etc., For the alcohol these factor are in considerable range. The burning of alcohol in diesel engine with the ceramic coating and brass material with various number of grooves, it can be considered as a preferable replacement for diesel fuel thereby promoting our economy and makes the farmers self sufficient.

The main advantages of this engine are lower fuel consumption, reduced noise and increased scuffing durability. These ceramic engines enable the use of low cetane fuels with its high operating temperatures. But with this, the performance of the lubricating oil deteriorates which further increases the friction in the chamber. All these lubricating oil problems can overcome with new solid or liquid lubricants.

\section{REFERENCES}

1. Roy Kamo, Walter Bryzik and Michael Reid, 1997, "Coatings for improving Engine Performance", SAE 970204.

2. Parker, D.A., and Donnison, G.M., 1999, "The Development of an Air Gap Insulated Piston", SAE Paper No. 990652.

3. Dhinagar, S.J., Nagalingam, B. and Gopalakkrishnan, K.V., 1997, "Use of Ceramics in Internal Combustion Engines", Proceedings of 10th National Conference on IC Engines and Combustion, India..

4. Tadeusz Hejwowski, 2010, "Comparative study of thermal barrier coatings for internal combustion engine", Vacuum 85.

5. T. Morrel, P.N. Blumberg and E.F. Fort, 1985, "Examination of key issues in LHR engines", SAE 850356.

6. R. Kamo, N.S. Mavinahally, L. Kamo, Bryzik, and E.E. Schwartz, 1997, "Injection Characteristics that improve performance of ceramic coated diesel engines", SAE 1997-01-0972.

7. Y. Miyairi, T. Matsuhisa, T. Ozawa, and N. Nakashima, 1998, "Selective heat insulation of combustion chamber walls for a DI Diesel engine with Monolithic Ceramics", SAE 980186.

8. S.H. Chan and K.A. Khor, 2000, "The effect of thermal barrier coated piston crown on engine characteristics", ASM International, 9-103-109.

9. Murthy, P.V.K., Murali Krishna, M.V.S, Sitaramaraju, A., 2010, " Performance Evaluation of Low Heat Rejection Diesel Engine with pure diesel", International Journal of Applied Engineering Research, Dindigul, Vol 1, No.3.

10. Pankaj N. Shrirao, and Anand N. Pawar, 2011, "An overview on thermal barrier coating (TBC) materials and its Effect on engine performance and emission", International Journal of applied research in mechanical engineering, Vol 1, 2011.

11. F.J. Wallance, T.K. Kao, M. Tarabad, W.D. Alexander, and A. Cole, 1997, "Thermally insulated diesel engine", Proc. of The Institution of Mech. Engg., Vol 198, No.:5,97-105.

12. P.R. Srivathsan, P.Terrin Babu, and S.Prabhakar, 2010, "Experimental Investigation on a low heat rejection engine", International Conference on Frontiers in Automobile and Mechanical Engineering at Sathyabama University, Chennai, Nov. 25-27.

13. G. Sivakumar, V. Shankar and G Hemath Kumar, 2012, "Is Thermal barrier coating for low heat rejection in SI engines or diesel engines", International Journal of Emerging Technology And Advanced Engineering, Vol 2(12). 
14. B. Nagalingam, S. Jabez Dhinagar, and K.V. Goplalakrishnan., 1995, "Spark assisted alcohol operation in low heat rejection engine", SAE 950059 15. C. Hasimoglu, 2008, "Exhaust emission characteristics of a Low heat rejection diesel engine fuelled with 10 percent ethanol and 90 percent diesel fuel mixture", Journal of Automobile Engineering, Vol 222(1), pp 93-100.

16. Alan C. Hansen., Qin Zhang., and Peter W.L. Lyne., 2005, "Ethanol-diesel fuel blends-a review" Bioresource Technology, Vol 96(3), pp 277-285.
17. Indian Petroleum and Petrochemicals Statistics 2009-2010, page 61, published by the Economics and Statistics Division, Department of Petroleum., Ministry of Petroleum, Chemicals and Fertilizers, Govt. of India.

18. Kenneth G. Budinski and Michael K. Budinski, Engineering Materials Properties and Selection, Prentice Hall publications, 2009. 